\title{
Penggunaan Konsep Fisika dalam Pertimbangan untuk menentukan Posisi Persalinan
}

\author{
Sri Suryani* \\ Jurusan Fisika, FMIPA-Universitas Hasanuddin \\ Kampus UNHAS - Jln. Perintis Kemerdekaan, \\ Tamalanrea, Makassar 90245
}

\begin{abstract}
Persalinan adalah proses pengeluaran hasil konsepsi setelah 40 minggu. Proses kehamilan dan persalinan adalah proses alamiah yang telah berlangsung sejak manusia ada di bumi ini. Oleh sebab itu proses persalinan sebaiknya mengikuti kaidah ilmu alam. Salah satu bagian dalam ilmu alam adalah ilmu Fisika. Hukum Newton yang membahas tentang gaya gravitasi merupakan bagian konsep Fisika yang dapat digunakan dalam mempertimbangkan posisi seorang ibu hamil untuk bersalin. Berdasarkan hal tersebut di atas, di dalam makalah ini akan dibahas tentang bentuk tubuh janin, posisi janin di dalam rahim, proses persalinan, dan posisi persalinan dipandang dari sisi ilmu Fisika. Hasil pembahasan ini dapat dimanfaatkan untuk pertimbangan dalam menolong seorang ibu hamil untuk bersalin, agar proses persalinan tersebut tidak meninggalkan trauma baik pada ibu maupun pada bayi yang dilahirkan.
\end{abstract}

\begin{abstract}
Birth delivery is a process of giving birth conception product after 40 weeks pregnancy. Pregnancy and giving birth are natural processes since man lived in this planet. Therefore, giving birth normally should follow nature's laws. One of the natural sciences is physics. Physics's laws especially Newton's Laws which discussed force of gravity can be used as a consideration to determine birth delivery's position. The reason is giving birth will be easier when force of gravity contribute in the process by pulling the fetus. So, baby's mother doesn't need to push the fetus out very hard. Considering those reasons, in this paper will discuss about body's structure of a fetus, fetus position in womb, birth delivery, and birth delivery's position from Newton's Laws point a view. Hopely, this paper could give other consideration to help pregnancy women when giving birth, in order to prevent traumatic experience for mother and the baby caused by longtime birth process.
\end{abstract}

KATA KUNCI: Newton's laws, gravity, birth delivery's position

\section{PENDAHULUAN}

Proses persalinan atau dikenal juga sebagai proses melahirkan adalah suatu proses pengeluaran hasil konsepsi setelah 40 minggu. Konsepsi atau pembuahan dikatakan juga sebagai pertemuan antara sel telur dan sperma. Sel telur yang telah dibuahi akan membelah dan berkembang menjadi embrio dan selanjutnya setelah usia kehamilan 12 minggu, disebut sebagai janin. Proses kehamilan normal umumnya berlangsung selama lebih kurang 40 minggu, dan setelah itu janin akan siap untuk keluar dari rahim, karena setelah 40 minggu, kualitas air ketuban menurun yang dapat meracuni janin, dan ukuran rahim sudah terlalu kecil untuk janin.

Seperti telah diketahui bahwa proses kehamilan dan persalinan adalah proses alamiah yang telah berlangsung sejak adanya manusia di bumi ini. Oleh sebab itu perkembangan janin dalam rahim akan mengikuti proses alamiah. Janin akan tumbuh dalam rahim dan menempati posisi yang sedemikian rupa, dengan tujuan untuk memudahkan proses persalinan. Ilmu Fisika yang merupakan bagian dari ilmu alam, dapat

\footnotetext{
*E-MAIL: sri_sumah@yahoo.com
}

digunakan untuk menjelaskan proses perkembangan janin ini dalam ketuban, sehingga ilmu Fisika khususnya dalam bidang mekanika dapat dimanfaatkan untuk mempertimbangkan posisi persalinan.

\section{TINJAUAN TEORI}

Proses perkembangan janin di dalam rahim diawali dengan proses konsepsi atau pembuahan atau bertemunya sel telur dan sperma. Minggu pertama hingga mencapai hari ke 50, pertumbuhan embrio belum nampak jelas berwujud manusia, karena pada saat ini sedang dibentuk organ luar, seperti tangan, kaki, telinga, wajah, dan jantung. Setelah 50 hari sejak terjadi konsepsi, embrio mulai terlihat seperti manusia, dan organ dalam mulai terbentuk, demikian pula jantung sudah mengambil alih peredaran darah, yang sebelumnya dilakukan oleh tali pusat. Selama perkembangan ini, posisi janin adalah duduk dengan kepala di sebelah atas, dan agak menunduk (Gambar 1).

Ukuran janin pada usia 8 minggu sekitar $40 \mathrm{~mm}$, sedangkan pada saat lahir mencapai $50 \mathrm{~cm}$. Oleh karena proses pertumbuhan tubuh berlangsung sangat cepat, maka pada minggu ke 28, janin mulai berputar, dan mempunyai posisi kepala di 


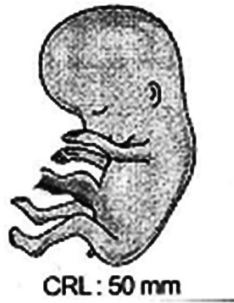

(a)

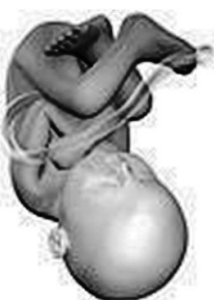

(b)
Gambar 1: (a) Janin usia 9 minggu, dan (b) Janin usia 40 minggu [1]

bawah dan bokong di atas. Posisi ini menetap hingga usia kehamilan 40 minggu, saat janin siap untuk lahir (Gambar 1).

Proses persalinan adalah proses pengeluaran janin dari rahim. Berbeda dengan perkiraan masyarakat awam yang menganggap bahwa proses ini sangat mudah, maka pada kenyataannya, pada saat proses persalinan, janin akan melakukan tiga gerakan utama, yaitu memutar kepala dengan sudut $90^{\circ}$ sambil menunduk agar dapat memasuki rongga panggul yang berbentuk oval. Setelah berada di rongga panggul dengan posisi belakang kepala di depan, maka janin siap meluncur keluar. Dalam istilah kebidanan, saat seperti ini disebut sebagai kala satu, yang ditandai dengan pembukaan serviks hingga $10 \mathrm{~cm}$. Kala dua adalah kala pengeluaran, yaitu proses janin ke luar yang ditandai dengan adanya kontraksi otot atau his, dan dorongan ibu untuk mengeran. Dan setelah kepala keluar, janin akan melakukan perputaran kembali dengan sudut $90^{\circ}$, untuk mengeluarkan bahu dan badan. Selanjutnya kala tiga adalah saat uri plasenta terlepas dari dinding uterus dan dilahirkan. Yang terakhir adalah kala empat yaitu lahirnya plasenta [2].

Proses persalinan adalah suatu proses yang dapat mengakibatkan traumatik baik pada ibu maupun pada janin. Rasa sakit yang berkepanjangan yang diakibatkan oleh proses persalinan yang lama dapat meninggalkan perasaan trauma pada ibu, bahkan pada bayi hingga di masa anak-anak dapat timbul halusinasi, seperti yang ditemukan oleh ahli psikoanalisis dr. Elizabeth Fehr [3]. Oleh sebab itu pertimbangan dalam memilih posisi persalinan menjadi sangat penting. Akibatnya dalam memilih posisi persalinan, maka ibu hamil berhak memutuskan sendiri, seperti yang diungkapkan oleh Doris Haire (1974) tentang hak pasien untuk berpartisipasi dalam pengambilan keputusan yang melibatkan kesejahteraan dirinya dan anak yang akan dilahirkan, kecuali ada kedaruratan medis, dalam buku The Pregnant Patient's Bill of Rights, yang diedarkan oleh Committee on Patient's Rights In New York [4].

\section{DISKUSI DAN PEMBAHASAN}

Pada awal kehamilan, janin mempunyai posisi duduk. Posisi ini baik untuk mengatur peredaran darah tubuh, karena pada saat ini terjadi pembentukan organ, seperti jantung, paruparu, ginjal, dan lain sebagainya. Pada trimester kedua atau usia kehamilan sekitar 20 minggu, seluruh organ sudah ter-
Variations of the breech presentation

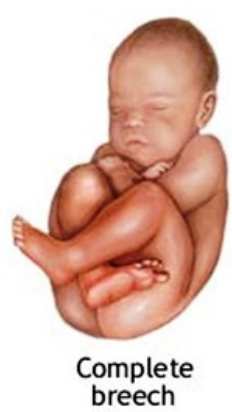

breech

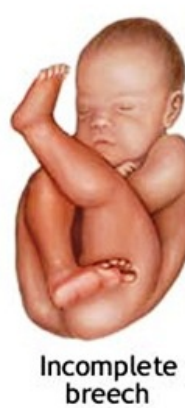

(a)

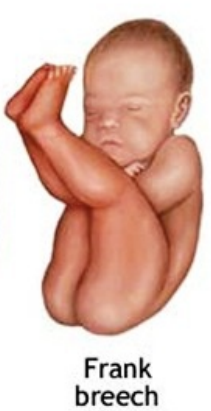

breech
Posisi melintang

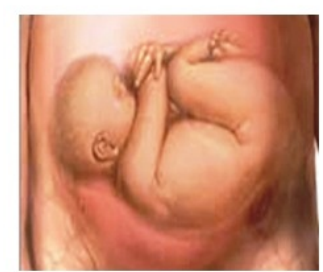

(b)

Gambar 2: Posisi janin normal dan sungsang (breech) [5].

bentuk walaupun belum mencapai ukuran yang seharusnya. Mulai saat ini janin akan tumbuh dengan cepat hingga mencapai ukuran $50 \mathrm{~cm}$.

Pada saat persalinan nanti, janin harus membuka jalan lahir. Untuk memudahkan pembukaan jalan diperlukan sesuatu yang berwujud bulat, dan pada tubuh manusia benda yang mempunyai wujud bulat adalah kepala bagian belakang dan juga bokong. Oleh sebab itu kepala bagian belakang atau bokong harus berada pada posisi di bawah pada saat janin siap lahir. Untuk mendapatkan posisi tersebut, maka gaya gravitasi bumi yang akan membantu memutarnya. Telah diketahui bahwa gaya gravitasi akan mudah menarik benda yang massanya besar. Dengan tujuan agar gaya gravitasi dapat mudah memutar kepala janin ke bawah, maka kepala janin mempunyai massa yang lebih besar dari badannya, atau sering dikatakan bahwa perkembangan kepala janin lebih cepat dari badan. Hal itulah yang menjadikan alasan agar ibu hamil mulai awal trimester ke dua dianjurkan banyak berjalan agar posisi janin baik. Ibu hamil yang tidak banyak bergerak mempunyai resiko mendapatkan janin pada posisi sungsang (Gambar 2), karena tidak dapat berputar, dan persalinan hanya dapat dilakukan melalui pembedahan.

Janin mempunyai posisi yang umum atau normal adalah kepala berada di bawah dengan bokong di bagian atas, dan posisi janin menyamping ibu. Bila janin sudah cukup umur yaitu setelah 40 minggu kehamilan, maka saatnya janin keluar, dan selanjutnya berkembang menjadi seorang manusia. Pada proses persalinan, umumnya dibantu oleh bidan ataupun dokter. Oleh sebab itu, posisi persalinan lebih sering ditentukan berdasarkan kenyamanan bidan atau dokter dalam bekerja. 


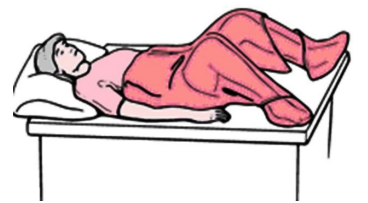

(a)

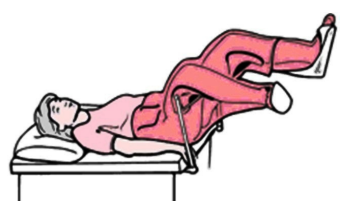

(b)

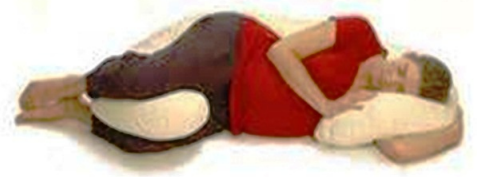

(c)

Gambar 3: Beberapa posisi persalinan: (a) dorsal recumbent, (b) litotomi, dan (c) berbaring ke samping kiri. [6].

Posisi persalinan yang umum digunakan hingga abad ke 18 adalah tegak (berdiri atau duduk), dan saat ini posisi yang sering digunakan adalah berbaring dengan punggung (dorsal recumbent), litotomi, berbaring dengan samping kiri, (Gambar 3) dan duduk setengah tegak (semi fowler) [7] .

Posisi berbaring digunakan agar dokter mudah bekerja, tetapi pada posisi ini, proses persalinan menjadi lebih lama karena kontraksi otot rahim harus lebih kuat, bahkan leher rahim terlipat. Sebaliknya pada posisi tegak, posisi dokter sangat sulit atau tidak nyaman, tetapi untuk janin tidak ada hambatan untuk mendorong serviks, sehingga akan mendorong ibu untuk mengeran, dan akibatnya persalinan akan lebih cepat. Di lain pihak, hukum Newton yang membahas tentang kesetimbangan statis (Hukum pertama) dan juga kesetimbangan dinamis (Hukum kedua) dapat digunakan untuk mengkaji gaya-gaya yang bekerja pada proses persalinan, sehingga akan diperoleh posisi yang tepat, dan akan menghasilkan suatu proses persalinan yang cepat dan aman. Pada makalah ini, hanya akan dibahas tentang proses persalinan normal, karena untuk posisi tidak normal, persalinan hanya dapat dilakukan melalui pembedahan.

Menentukan posisi persalinan dapat dilakukan dari pandangan ilmu Fisika, khususnya mekanika. Di dalam mekanika, dikenal besaran yang disebut gaya (F). Gaya ini merupakan besaran vektor, dan mempunyai beberapa jenis seperti gaya gravitasi atau berat / weight, gaya gesek, gaya pegas, dan lainlain. Oleh karena gaya merupakan besaran vektor, maka operasi gaya harus menggunakan vektor analisis. Dalam membahas tentang gaya, maka hukum yang menyertainya adalah hukum Newton, yang terdiri dari 3 hukum:[8]

1. Hukum I Newton adalah hukum kesetimbangan translasi atau $\sum \mathbf{F}=0$

2. Hukum II Newton adalah hukum dinamika atau $\sum \mathbf{F}=$ $\left(\sum \mathrm{m}\right)$ a dengan $\mathrm{m}$ adalah massa benda, dan a adalah percepatan benda.

3. Hukum III Newton adalah hukum aksi - reaksi.

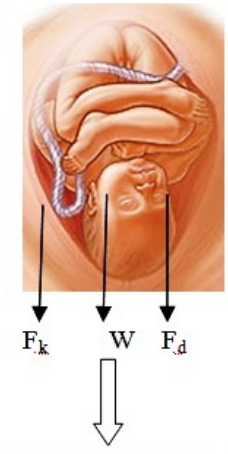

Arah keluarnya janin

(a)

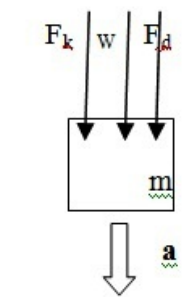

Arah keluarnya janin

(b)
Gambar 4: Posisi tegak.

Proses persalinan normal kenyataanya adalah proses keluarnya janin, yang dalam hal ini dapat diartikan sebagai gerakan suatu benda dengan massa $m$. Akibatnya dengan mengetahui jenis gaya yang bekerja, serta memanfaatkan hukum Newton dengan operasi penjumlahan vektor, maka dapat dijelaskan kelebihan dan keuntungan berbagai posisi persalinan normal. Pada saat proses persalinan, penentuan posisi untuk persalinan memerlukan beberapa pertimbangan, diantaranya adalah kenyamanan ibu dan juga janin. Ibu hamil dan juga janin seharusnya tidak perlu merasakan sakit yang berkepanjangan, karena proses persalinan dapat berjalan dengan cepat. Dengan mempertimbangkan gaya yang bekerja pada proses persalinan, yaitu gaya kontraksi otot rahim, gaya gravitasi bumi, dan gaya dorong (gaya eran), maka dengan menggunakan mekanika yaitu hukum Newton, dapat disarankan beberapa posisi persalinan.

\section{Posisi tegak (berdiri, duduk, dan jongkok).}

Pada Gambar 4, $\mathrm{F}_{k}$ adalah gaya kontraksi otot rahim, W adalah gaya tarik grafitasi bumi yang setara dengan massa bayi, $\mathrm{F}_{d}$ adalah gaya eran atau gaya dorong yang dilakukan oleh ibu. Untuk gaya gesek tidak ada, karena adanya air ketuban yang pecah sesaat sebelum proses persalinan berlangsung, sehingga jalan lahir menjadi licin.

Bila ditinjau dari vektor gaya, maka semua gaya yang bekerja pada janin mempunyai arah yang sama, sehingga kecepatan keluarnya janin sangat ditentukan oleh gaya dorong /eran ibu, karena diasumsikan gaya kontraksi otot dan grafitasi adalah konstan atau tidak berubah. Bila $\sum \mathbf{F}=\mathrm{m}$ a, maka $\mathbf{F}_{k}$ $+\mathbf{W}+\mathbf{F}_{d}=\mathrm{m}$ a atau $\mathbf{F}_{d}=\mathrm{m} \mathbf{a}-\left(\mathbf{F}_{k}+\mathbf{W}\right)$. Selain itu dengan bantuan gaya gravitasi, maka kekuatan ibu untuk mengeran atau mendorong tidak perlu besar.

\section{Posisi berbaring (berbaring samping ke kiri, dorsal} recumbent, dan litotomi)

Pada Gambar 5 terlihat bahwa W pada posisi berbaring sama dengan nol atau tidak ada bantuan gaya tarik gravitasi bumi, 


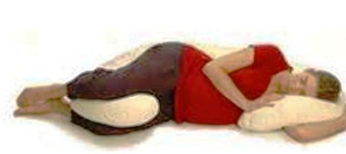

(a)

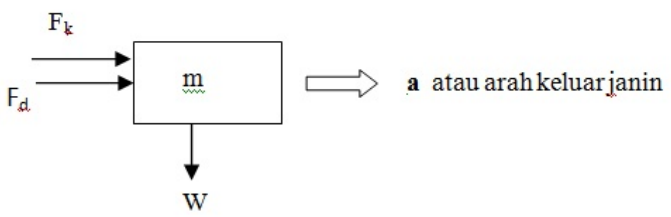

(c)

Gambar 5: Posisi berbaring.

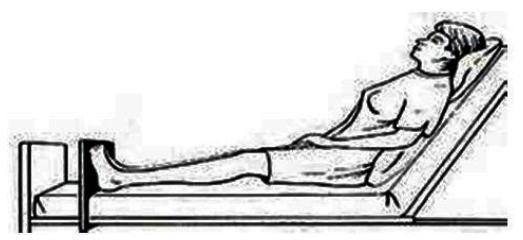

(a)

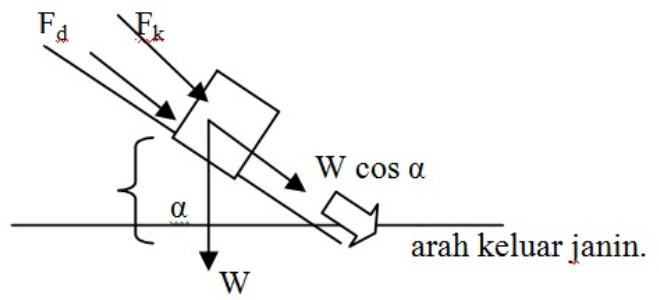

(b)

Gambar 6: Posisi setengah duduk dan tegak.

sehingga kecepatan keluarnya janin hanya ditentukan oleh gaya kontraksi otot rahim dan gaya eran ibu, atau dalam bentuk matematika $\mathrm{m} \mathbf{a}=\mathbf{F}_{k}+\mathbf{F}_{d}$. Dengan kata lain, kecepatan proses persalinan sangat ditentukan oleh kekuatan ibu mengeran. Dengan kata lain, ibu harus mendorong dengan kuat.

Dalam ilmu kebidanan, posisi berbaring ke kiri atau ke kanan bergantung pada posisi punggung janin, sambil merangkul satu kaki yang ada di atas, dan posisi dapat dilakukan untuk mengeran.

\section{Posisi setengah duduk dan tegak atau semi fowler.}

Posisi semi fowler adalah posisi setengah duduk, dengan besar sudut yang dibentuk antara kaki dan badan adalah antara $35-45^{\circ}$ (Gambar 6). Diagram vektor gaya dapat diasumsikan sebagai sebuah benda yang berada di bidang miring.

Dengan menggunakan hukum II Newton yaitu $\sum \mathbf{F}=\mathrm{m}$ a, maka $\mathbf{F}_{k}+\mathbf{W} \cos \alpha+\mathbf{F}_{d}=\mathrm{m}$ a atau $\mathbf{F}_{d}=\mathrm{m} \mathbf{a}-\left(\mathbf{F}_{k}\right.$ $+\mathbf{W} \cos \alpha$ ). Hal ini dapat diartikan bahwa pada posisi semi fowler gaya gravitasi bumi masih memberi pengaruh, walaupun tidak besar, yaitu $82 \%$ untuk sudut $\alpha$ sama dengan $35^{\circ}$, dan $71 \%$ untuk sudut $\alpha$ sama dengan $45^{\circ}$ dari berat janin (W). Akibatnya ibu hamil tidak harus mendorong atau mengeran dengan kuat, karena masih ada bantuan dari gaya tarik gravitasi bumi, dan proses persalinan dapat lebih cepat.

Posisi semi fowler ini dapat dilakukan dengan cara merangkul ke dua paha sampai batas siku, dan kepala sedikit diangkat, sehingga dagu mendekati dada, dan ibu dapat melihat perutnya. Keadaan ini dilakukan bila tempat tidur yang dapat diatur ketinggiannya, tidak tersedia.

Dari pembahasan di atas, yang meliputi tiga posisi utama, yaitu berdiri, berbaring, dan setengah duduk, dapat terlihat beberapa kelebihan dan kekurangan baik bagi ibu hamil sendiri ataupun bagi dokter. Oleh sebab itu, saat ini seorang bidan wajib memberi informasi tentang kelebihan dan kekurangan posisi persalinan yang akan dipilih oleh seorang ibu hamil, sehingga ibu hamil dapat memutuskan posisi yang nyaman bagi dirinya dan tidak terlalu menyulitkan dokter atau bidan.

\section{SIMPULAN}

Proses persalinan adalah proses alami, demikian pula hukum Newton yang membahas tentang alam. Bentuk tubuh janin dan posisi janin di dalam rahim diciptakan agar persalinan dapat berlangsung dengan cepat dan mengurangi trauma persalinan pada ibu. Dengan menggunakan hukum Newton, hal tersebut di atas dapat dipahami, sehingga dalam menentukan posisi bersalin dapat menggunakan vektor gaya dan hukum kesetimbangan Newton sebagai salah satu pertimbangan.
[1] Wikipedia, Fetus, [Internet] available from: http://en.wikipedia.org/wiki/File:40-weeks-pregnant.jpg, (diakses tanggal 10 Mei 2011).

[2] H. Wiknyosastro, Ilmu Kebidanan (edisi 3, editor: Abdul Bari Saifuddin dkk., Penerbit Yayasan Bina Pustaka Sarwono Prawirohardjo, 2007).
[3] Diagram group, Woman's Body (terjemahan oleh Penerbit Gunung Jati, Jakarta, 1998).

[4] Varney H, J.M. Kriebs, C. Gegor, Varney's Midwifery $\left(4^{\text {th }}\right.$ ed, 2004, terjemahan oleh Ana Lusiyana dkk, Penerbit EGC, Jakarta, 2006). 
[5] Fisher R, Breech Presentation, emedicinehealth (Editor: David Chelmow, MD, up-date tanggal 14 April 2011), [Internet] available from : http://www.emedicinehealth.com/script/main/ art.asp?articlekey $=136587 \&$ ref=128675 (diakses tanggal 10 Mei 2011).

[6] Scribd.com, Dorsal Recumbent, [internet] available from : http://www.scribd.com/doc/42938773/Posisi-Dorsal-Recumbent (diakses tanggal 10 Mei 2011).

[7] T. Oktaviany, Posisi Melahirkan Tren 2010 (Okezone.com: Lifestyle, 25 Januari 2010).

[8] D. Halliday, and R. Resnick, Physics - Parts I and II (John Wiley and Sons, Inc., New York, 1980). 